\title{
A Study on Profile Characteristics of Rural Women Having Children between the Age Group of 6 Month to 24 Month
}

\author{
Lopamudra Mohapatra $^{1 *}$, R. Neela Rani ${ }^{1}$, R. Geetha Reddy ${ }^{1}$ and T. Kamalaja ${ }^{2}$ \\ ${ }^{1}$ Department of Extension Education and Communication Management, Hyderabad, \\ Professor Jayashankar Telangana State Agricultural University, Telangana, India \\ ${ }^{2}$ Department of Food and Nutrition, Hyderabad, Professor Jayashankar Telangana State \\ Agricultural University, Telangana, India
}

*Corresponding author

\begin{tabular}{|l|}
\hline \multicolumn{1}{|l|}{} \\
\hline Ke y w o r d s \\
Empowerment, \\
$\begin{array}{l}\text { Food security, } \\
\text { Malnutrition, Mass } \\
\text { media, Extension } \\
\text { contact }\end{array}$ \\
\hline Article Info \\
\hline $\begin{array}{l}\text { Accepted: } \\
\text { 22 June 2020 } \\
\text { Available Online: } \\
\text { 10 July } 2020\end{array}$ \\
\hline \hline
\end{tabular}

\section{A B S T R A C T}

The present study was undertaken to study the profile characteristics of rural women having children between 6 month and 24 months of age. A total sample of 120 rural mothers was selected through purposive random sampling method. Ex-post facto research design was used for the study. The study was conducted by using a structured interview schedule. The data was analysed using frequency and percentage. In the study the result revealed that majority of the respondents were belonged to the age of $<25$ year $(60 \%)$, were illiterate $(25.84 \%)$, had agriculture $(36.67 \%)$ as occupation, nuclear family $(67.50 \%)$, medium income $(50.83 \%)$, small land holding $(50 \%), 1$ to 2 children $(79.16 \%)$, low mass media exposure $(74.17 \%)$ and low extension contact $(90.83 \%)$.

\section{Introduction}

Rural women are active agents of economic and social change in many ways and to various degrees, whereas they have constrained in their roles as farmers, producers, investors, caregivers and consumers. They play crucial roles ensuring food and nutrition security, eradicating rural poverty and improving the well-being of their families. Still the women continue to face serious challenges as a result of gender-based stereotypes and discrimination that deny them equitable access to opportunities, resources, assets and services. It was seen that mothers empowerment have a positive impact on the nutritional status of their child. In the context of child health outcomes, given that women are typically the primary caretakers of children, redirecting of decision-making roles in favour of women has the potential to improve child health outcomes. Although 
there has been a decline in the rates of moderately underweight and stunted children, India continues to have one of the worst levels of low birth weight and underweight children when compared to other nations. The indicators of women's empowerment, such as the education of the mother and employment status had a negative relationship with child malnutrition Shafiq (2019).

The profile characteristic of women plays a major to increase the knowledge and empower them in all the aspects. By taking the above points from the situation the study was conducted to find out the profile characteristic of rural women.

\section{Materials and Methods}

In the present study Ex-post facto research design was followed. Medak district was selected. From the selected district, randomly 4 mandals were selected and total of 8 villages were selected randomly. From each village 15 respondents were selected purposively those who were having child between the age of 6 month to 24 month. Thus a total of 120 samples were selected for the present study. An interview schedule was used by doing suitable modifications. The data was organized, tabulated and classified using qualitative and quantitative classification and subjected to statistical tests. The statistical tools were Frequency and percentage.

\section{Results and Discussion}

\section{Age}

From table no. 1 it could be concluded that majority of the respondents $(60 \%)$ were belonged to the age group of less than 25 years followed by 25 to 35 years $(30.83 \%)$ and more than 35 years $(09.17 \%)$. The reason might be that majority of the respondents got married early which leads to early conception of child. Hence majority of the respondents were from less than 25 years.

\section{Education}

From table 1 it could be depicted that most of the respondents $(25.84 \%)$ were illiterate followed by high school education $(23.33 \%)$, primary school $(20.84 \%)$, college education $(18.66 \%)$ and middle school education (13.33\%). Education is one of the asset which will create awareness about good nutrition and health among rural women. But from the study it could be found out that about half of the respondents are illiterates and had education up to primary school.

\section{Occupation}

From table 1 it could be found out that majority of the respondents $(36.67 \%)$ had agriculture as their occupation followed by housewife $(33.33 \%)$, labour $(20.83 \%)$, small business $(07.50 \%)$ and government job $(01.67 \%)$. Most of the respondents occupation were agriculture due to the reason that as most of the respondents were illiterates so they were working in their own land. Also as the respondents were mothers of 6-24 months of child so they are staying at home as housewife.

\section{Income of family}

From table 1 it could be revealed that majority of the respondents $(50.83 \%)$ belonged to the middle income group followed by low income $(47.50 \%)$ and high income $(1.67 \%)$. The main reason might be as most of the respondent occupation was agriculture and housewife.

\section{Family type}

From table 1 it could be found out that majority of the respondents $(67.50 \%)$ were belonged to the nuclear family followed by 
joint family $(30.00 \%)$ and extended family $(02.50 \%)$. This may be due to the joint family tradition of the system changed from extended to nuclear families because of the modern economic \& social development in society.

\section{Land holding}

From table 1 it could be depicted that majority of the respondents (50\%) were belonged to the category of small land holding followed by marginal land holding $(28.34 \%)$, semi- medium land holding $(13.33 \%)$ and medium land holding $(08.33 \%)$.

\section{Number of children}

From table no. 1 it could be concluded that majority of the respondents $(79.16 \%)$ had 1 to 2 children followed by 3 to 4 children $(20.84 \%)$. The reason might be increased awareness by different national and international programmes for controlling the population growth.

\section{Age of the child}

From table 2 it could be depicted that majority of the respondents $(54.17 \%)$ had child between the age group of 12 to 24 month followed by 6 to 8 months (25\%) and 9 to 11 months (20.83\%). Majority of the children were coming in between 12 to 24 months because of the time taken in this category was 12 month were as the other two age category had only two months of time.

\section{Gender of the child}

From table 2 it could be stated that majority $(59.17 \%)$ of the respondents had male child followed by female child (41.83\%). The reason might be low sex ratio in India i.e., 943 females per 1000 male (Census 2011).

\section{Birth order of the child}

From table 2 it could be concluded that among the respondents, majority $(50 \%)$ of them had first child followed by second child $(35 \%)$ and third child $(15 \%)$. A number of researcher show a great influence of birth order contributes child's behaviour, career choice, intelligence of child to certain degree but the child born in order of first, second, last or any other doesn't have great importance Gupta (2019).

\section{Birth weight of the child}

From table 2 it could be found out that majority $(55 \%)$ of the child's birth weight were between the category of $2600-3000 \mathrm{~g}$ followed by more than 3000g (31.67\%) and $2100-2500 \mathrm{~g}(13.33 \%)$. From the study we got that majority of the children were having normal birth weight.

\section{Type of delivery}

From table 3 it could be found out that majority $(59.17 \%)$ of the respondents had given birth through normal delivery followed by caesarean delivery $(40.83 \%)$. Though caesarean delivery rate is increasing in India from 7.1 NFHS-2 to 10.2 in NFHS-3 but still majority of the respondents in rural preferred normal delivery due to fear of caesarean delivery.

\section{Mass Media Exposure}

From table 3 it could be found out that majority $(90.83 \%)$ of the respondents had low mass media exposure followed by medium $(21.66 \%)$ and high (04.17\%) mass media exposure. As most of time respondents were engaged into agriculture and household work which they were hindering them to get exposed into mass media. The another reason might be the illiteracy and low income level among the respondents. 
Table.1 Distribution of rural women according to their profile characters

\begin{tabular}{|c|c|c|c|}
\hline S. No. & Category & Frequency & $\begin{array}{l}\text { Percentage } \\
(\%)\end{array}$ \\
\hline \multicolumn{2}{|l|}{1.} & \multicolumn{2}{|c|}{ Age } \\
\hline a) & $<25$ & 72 & 60.00 \\
\hline b) & $25-35$ & 37 & 30.83 \\
\hline c) & $>35$ & 11 & 09.17 \\
\hline \multicolumn{2}{|l|}{2.} & \multicolumn{2}{|c|}{ Education } \\
\hline a) & Illiterate & 31 & 25.84 \\
\hline b) & Primary School & 25 & 20.84 \\
\hline c) & Middle School & 16 & 13.33 \\
\hline d) & High School & 28 & 23.33 \\
\hline e) & College education & 20 & 18.66 \\
\hline \multicolumn{2}{|l|}{3.} & \multicolumn{2}{|c|}{ Occupation } \\
\hline a) & Agriculture & 44 & 36.67 \\
\hline b) & Labour & 25 & 20.83 \\
\hline c) & Small business & 9 & 07.50 \\
\hline d) & Government job & 2 & 01.67 \\
\hline e) & Housewife & 40 & 33.33 \\
\hline \multicolumn{2}{|l|}{4.} & \multicolumn{2}{|c|}{ Income of Family (Annual in Rupees) } \\
\hline a) & Low income (Below 60,000) & 57 & 47.50 \\
\hline b) & Medium income $(60,000-1,20,000)$ & 61 & 50.83 \\
\hline c) & High income (above $1,20,000$ ) & 02 & 01.67 \\
\hline \multicolumn{2}{|l|}{5.} & \multicolumn{2}{|c|}{ Familv Type } \\
\hline a) & Nuclear Family & 81 & 67.50 \\
\hline b) & Joint Family & 36 & 30.00 \\
\hline c) & Extended family & 03 & 02.50 \\
\hline \multicolumn{2}{|l|}{6.} & \multicolumn{2}{|c|}{ Land Holding } \\
\hline a) & Marginal holding & 34 & 28.34 \\
\hline b) & Small holding & 60 & 50.00 \\
\hline c) & Semi- medium holding & 16 & 13.33 \\
\hline d) & Medium holding & 10 & 08.33 \\
\hline e) & Large holding & 0 & 00.00 \\
\hline \multicolumn{2}{|l|}{7.} & \multicolumn{2}{|c|}{ Number of children } \\
\hline a) & $1-2$ & 95 & 79.16 \\
\hline b) & $3-4$ & 25 & 20.84 \\
\hline c) & Above 4 & 0 & 00.00 \\
\hline
\end{tabular}


Table.2 Distribution of rural women according to the General information about their child

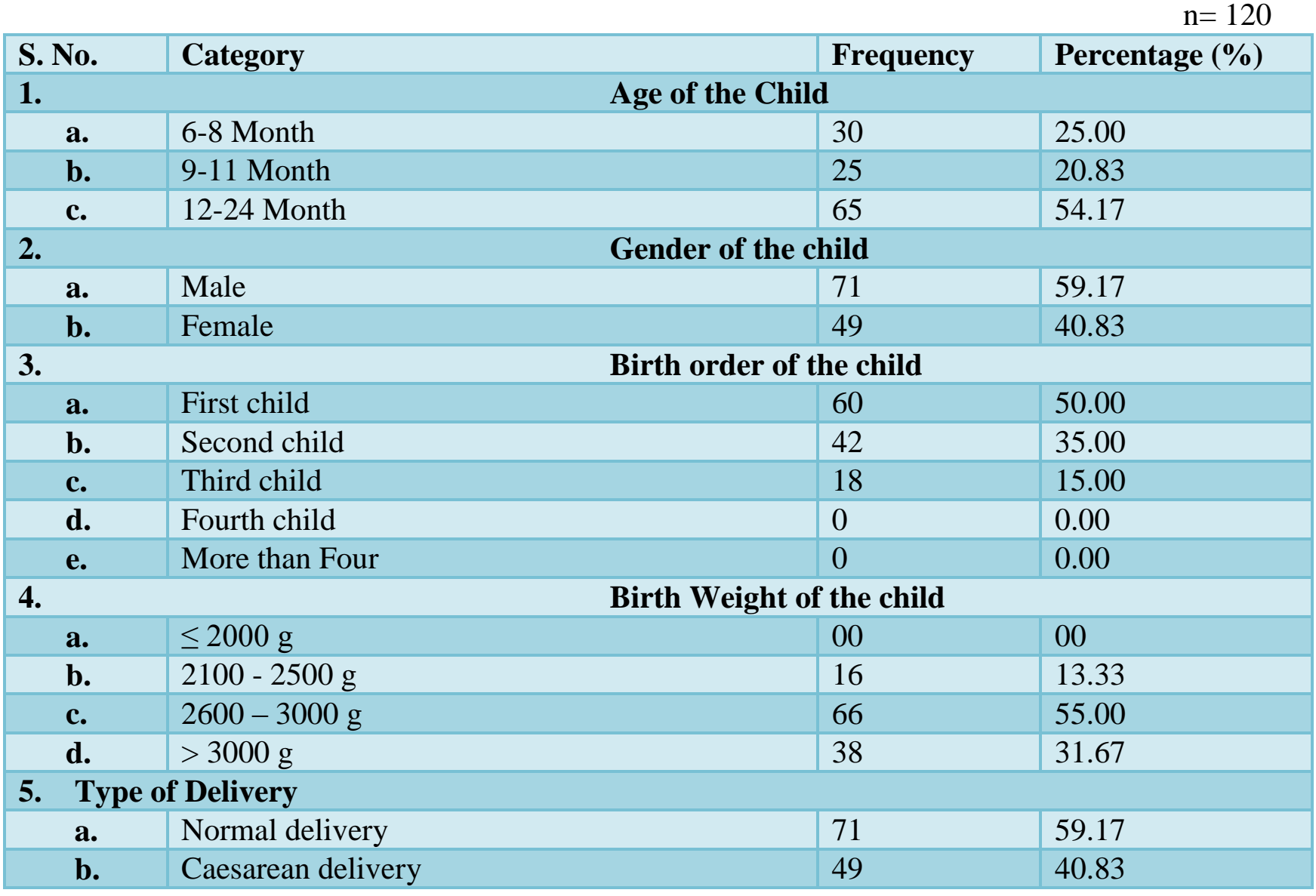

Table.3 Distribution of rural women according to the Mass Media Exposure

\begin{tabular}{|r|l|l|l|}
\hline S.No. & Mass Media Exposure & Frequency & Percentage (\%) \\
\hline a. & Low & 89 & 74.17 \\
\hline b. & Medium & 26 & 21.66 \\
\hline c. & High & 05 & 4.17 \\
\hline
\end{tabular}

Table.4 Distribution of rural women according to the Extension Contact

\begin{tabular}{|r|l|l|l|}
\hline S.No. & Extension Contact & Frequency & Percentage (\%) \\
\hline a. & Low (8-18) & 109 & 90.83 \\
\hline b. & Medium (19-29) & 11 & 09.17 \\
\hline c. & High (30-40) & 00 & 00 \\
\hline
\end{tabular}

\section{Extension contact}

From table 3 it could be found out that majority of the respondents $(90.83 \%)$ had low extension contact followed by medium
$(21.66 \%)$ and high $(04.17 \%)$ extension contact. The reason for these results of low extension contact may be due to illiteracy, shyness, ignorance which inhibits them to get into contact with extension personnel. It was 
also observed that respondents had good contacts with Anganwadi workers when compared to other extension personnel. The findings were similar with the findings of Deepika (2019).

\section{References}

Bidwe, A.R. 2018. Study on Infant and Young child feeding practices, formulation of weaning foods and their popularization. PhD. Thesis. Vasantrao Naik Marathwada Krishi Vidyapeeth, Parbhani, India.

Deepika, K.S. 2019. Effect of child discrimination on the education of girl child in rural and tribal areas of Telangana state. M.Sc. Thesis. Professor Jayashankar Telangana State Agricultural University, Hyderabad, India.

Gupta, V. 2019. A study on complementary feeding practices prevalent in rural areas of Faizabad District. Ph.D Thesis. Sam Higginbottom University of Agriculture, Technology and Sciences, Allahabad (Prayagraj), India.

Islam, M and Mustaquim, MD. 2014. Socio economic status of rural population an income level analysis. Asian academic research Journal of multidisciplinary. 1 (24): 98-106.

Manjunatha, B.R and Gangadhar, M.R. 2018. Socio-Economic Status of the Bettakuruba Tribal Women: a Case Study from the Chamarajanagara District, Karnataka. Antrocom Journal of Anthropology. 14 (1): 129-137.

Shafiq, A., Hussain, A., Asif, M., Hwang, J., Jameel, A. and Kanwel, S. The Effect of "Women's Empowerment" on child Nutritional Status in Pakistan. International Journal of Environmental Research and Public Health.

\section{How to cite this article:}

Lopamudra Mohapatra, R. Neela Rani, R. Geetha Reddy and Kamalaja, T. 2020. A Study on Profile Characteristics of Rural Women Having Children between the Age Group of 6 Month to 24 Month. Int.J.Curr.Microbiol.App.Sci. 9(07): 3649-3654. doi: https://doi.org/10.20546/ijcmas.2020.907.427 